\title{
Prognostic impact of prognostic nutritional index in advanced (stage IIIB/IV) non-small cell lung cancer patients
}

\author{
X. L. LI' ${ }^{1}$, Z. H. YAO ${ }^{2}$, Y. Y. WAN ${ }^{2}$, X. Y. MOU ${ }^{1}$, Y. H. NI' ${ }^{1}$, E. L. SUN ${ }^{1}$, D. ZANG ${ }^{1}$, D. J. LIN ${ }^{2, *}$ \\ ${ }^{1}$ Department of Healthcare Respiratory Medicine, Shandong Provincial Hospital Affiliated to Shandong University, Shandong University, Jinan, \\ Shandong, China; ${ }^{2}$ Department of Respiratory Medicine, Shandong Provincial Hospital Affiliated to Shandong University, Shandong University, \\ Jinan, Shandong, China
}

${ }^{*}$ Correspondence: qianqian037@163.com

Received January 25, 2019 / Accepted March 28, 2019

\begin{abstract}
Prognostic nutritional index (PNI) is a parameter reflecting prognosis for various cancers, including resected lung cancer. However, there were few reports to study the relationship between the PNI and overall survival (OS) in patients with advanced (stage IIIB/IV) non-small lung cancer (NSCLC). In this study, we collected the clinical data of 315 patients with advanced (stage IIIB/IV) NSCLC who had received chemotherapy or epidermal growth factor receptor (EGFR)-tyrosine kinase inhibitors (TKIs) between January 2010 and June 2011. Survival curves were plotted using the Kaplan-Meier method. Multivariate analyses were used to evaluate prognostic significance of PNI in patients with advanced (stage IIIB/IV) NSCLC. In our analysis, we found that PNI ( $\mathrm{p}=0.001)$ was significantly associated with OS in patients with advanced (stage IIIB/ IV) NSCLC, so was smoking $(\mathrm{p}<0.001)$ and disease stage $(\mathrm{p}=0.005)$. We demonstrated that PNI could be utilized to predict survival outcomes in patients with advanced (stage IIIB/IV) NSCLC. Patients with a lower PNI may have worse prognosis.
\end{abstract}

Key words: non-small cell lung cancer, prognostic nutritional index, prognosis

Lung cancer remains the leading malignancy in terms of morbidity (11.6\%) and mortality (18.4\%) in the world, according to authoritative statistics from "Global cancer statistics 2018" [1]. By 2017, the incidence of lung cancer in China has risen to 800,000 and the death toll has reached 700,000 , accounting for a quarter of all cancer deaths. Non-small cell lung cancer (NSCLC) accounts for approximately $80 \%$ of all lung cancers [2].

Surgical treatment is the preferred treatment for NSCLC, but most lung cancer patients are stage IIIB and IV when diagnosed and lost the opportunity of radical resection. Thus, it is important for early detection of lung cancer. Currently, TNM staging is regarded as a crucial tool for clinical prognosis and outcome in lung cancer. Besides, it is reported that some biomarkers that indicate systemic inflammatory responses, simple and measurable, have been used to predict prognosis across multiple malignancies, including neutrophil lymphocyte ratio (NLR) $[3,4]$ and platelet lymphocyte ratio (PLR) $[5,6]$.

In recent years, prognostic nutritional index (PNI) which was used to assess immune-nutritional status of patients receiving gastrointestinal surgery $[7,8]$ has been identified to be a prognostic factor of cancers, such as liver, gastric and esophageal cancer and pleural mesothelioma [9-13]. Many studies have suggested the prognostic value of PNI in patients with resectable lung cancer [14]. However, PNI in patients with advanced NSCLC has not previously been elucidated.

In the present study, we investigated the prognostic value of the PNI among patients with advanced (IIIB/IV) NSCLC who had no chance to receive surgery.

\section{Patients and methods}

Patients characteristics. The patients' characteristics are presented in Table 1 . This study comprised 333 patients with primary NSCLC who had received chemotherapy or epidermal growth factor receptor (EGFR)-tyrosine kinase inhibitors (TKIs) in Shandong Provincial Hospital between 2010 and 2011. All the patients included in the analysis were diagnosed with stage IIIB or IV lung cancer who had no chance to receive surgery. All laboratory data was collected before treatment. Patients with autoimmune diseases, previous or coexisting cancers other than NSCLC or hematological disorders were excluded. Of these, 18 patients were excluded. All patients provided informed consent prior to this study. This study was conducted with the approval of 
Table 1. Clinicopathological characteristics of patients with NSCLC cancer $(\mathbf{n}=315)$.

\begin{tabular}{ll}
\hline Factor & Number (\%) \\
\hline Age (years) & $130(41.3 \%)$ \\
$\quad<58$ & $185(58.7 \%)$ \\
$\quad \geq 58$ & \\
Gender & $102(32.4 \%)$ \\
$\quad$ Female & $213(67.6 \%)$ \\
$\quad$ Male & \\
Smoking & $205(65.1 \%)$ \\
$\quad$ No smoking & $110(34.9 \%)$ \\
Smoking & \\
Disease stage & $143(45.4 \%)$ \\
IIIB & $172(54.6 \%)$ \\
IV & \\
Treatment & $240(76.2 \%)$ \\
Chemotherapy & $75(23.8 \%)$ \\
EGFR-TKIs & \\
PNI & $179(56.8 \%)$ \\
$<50$ & $136(43.2 \%)$ \\
$\geq 50$ & \\
Pathology & $110(34.9 \%)$ \\
SQ & $162(51.4 \%)$ \\
AD & $43(13.7 \%)$ \\
Others &
\end{tabular}

$\mathrm{AD}$, adenocarcinoma; PNI, prognostic nutritional index; SQ, squamous cell carcinoma; EGFR-TKIs, epidermal growth factor receptor (EGFR)-tyrosine kinase inhibitors.

Table 2. Relationship between PNI and clinicopathological features.

\begin{tabular}{lccc}
\hline Factors & PNI $\geq \mathbf{5 0}$ & PNI $<50$ & p-value \\
Age (years) & & & 0.175 \\
$\quad<58$ & $62(45.6 \%)$ & $68(38 \%)$ & \\
$\quad 258$ & $74(54.4 \%)$ & $111(62 \%)$ & \\
Gender & & & 0.335 \\
$\quad$ Female & $48(35.3 \%)$ & $54(30.2 \%)$ & \\
$\quad$ Male & $88(64.7 \%)$ & $125(69.8 \%)$ & \\
Smoking & & & 0.284 \\
Smoking & $43(31.6 \%)$ & $67(37.4 \%)$ & \\
$\quad$ No smoking & $93(68.4 \%)$ & $112(62.6 \%)$ & \\
Disease stage & & & $<0.001$ \\
IIIB & $81(60 \%)$ & $62(34.6 \%)$ & \\
IV & $55(40 \%)$ & $117(65.4 \%)$ & \\
Treatment & & & 0.049 \\
Chemotherapy & $111(81.6 \%)$ & $129(72.1 \%)$ & \\
EGFR-TKIs & $25(18.4 \%)$ & $50(27.9 \%)$ & \\
Pathology & & & 0.49 \\
AD & $75(55.2 \%)$ & $87(48.6 \%)$ & \\
SQ & $43(31.6 \%)$ & $67(37.4 \%)$ & \\
Others & $18(13.2 \%)$ & $25(14 \%)$ & \\
\hline
\end{tabular}

$\mathrm{AD}$, adenocarcinoma; PNI, prognostic nutritional index; EGFR-TKIs, epidermal growth factor receptor (EGFR)-tyrosine kinase inhibitors; SQ, squamous cell carcinoma. the institutional Ethics Committee of Shandong Provincial Hospital Affiliated to Shandong University.

Data collection and definition. The clinical characteristics of patients in our study including age, sex, history of tobacco exposure, pathological type, TNM stage and the details of treatment were collected by electronic medical records. Computed tomography (CT) was carried out before treatment. A total of $240(76.2 \%)$ patients received systemic chemotherapy for at least two cycles. The remaining 75 (23.8\%) patients were treated with EGFR-TKIs. Blood sample collection was routinely performed before the initiation of any treatment, including serum albumin and lymphocyte count. Then, the PNI was calculated as $10 \times$ serum albumin $(\mathrm{g} / \mathrm{dl})+0.005 \times$ total lymphocyte count $\left(\right.$ per $\left.\mathrm{mm}^{3}\right)[10]$. The PNI cut-off value for clinically significant malnutrition was set at below 50 in this approach.

Patient follow-up. Follow-up was performed for all patients every 3 months for the first 2 years, every 3-6 months for 2-5 years until September 1, 2016. The follow-up included reviewing the patient's medical history, blood routine, tumor markers, biochemical examination. In addition, chest x-ray films or CT scans were performed at least twice per year. The period from the therapy to the date of death was defined as the OS time.

Statistical analysis. Statistical analysis was performed using SPSS for Windows version 22.0 (SPSS, Chicago, IL, USA). The $\chi^{2}$ test was used to compare categorical variables. OS was calculated from the date of therapy to the date of NSCLC-associated death. The Kaplan-Meier method was used to estimate the survival rates for different groups and the equivalences of the survival curves were tested by log-rank statistics. The proportional hazards assumption was explored using log-minus-log-plots. The Cox proportional hazards model was used for univariate and multivariate survival analysis (multivariate survival analysis consisted of variables with $\mathrm{p}$-value $<0.05$ in univariate analysis). A $\mathrm{p}<0.05$ was considered statistically significant.

\section{Results}

Patients characteristics. A total of 315 patients with NSCLC were eligible for analysis. The age of patients ranged from 26 to 79 years (mean, 58.53 years). Of these patients, $213(67.6 \%)$ were males and $102(32.4 \%)$ were females; 110 (34.9\%) patients smoked. According to TNM classification, there were 143 patients $(45.4 \%)$ in pathological stage IIIB and 172 patients $(54.6 \%)$ in stage IV. A total of $240(76.2 \%)$ patients received systemic chemotherapy and $75(23.8 \%)$ patients EGFR-TKIs. There were 162 (51.4\%) patients with adenocarcinoma, 110 (34.9\%) with squamous cell carcinoma, and $43(13.7 \%)$ with other histological types. The baseline characteristics of the 315 patients are shown (Table 1).

Association of PNI with clinicopathological characteristics. Table 2 shows the relationship between PNI and the clinicopathological features. Significant differences 


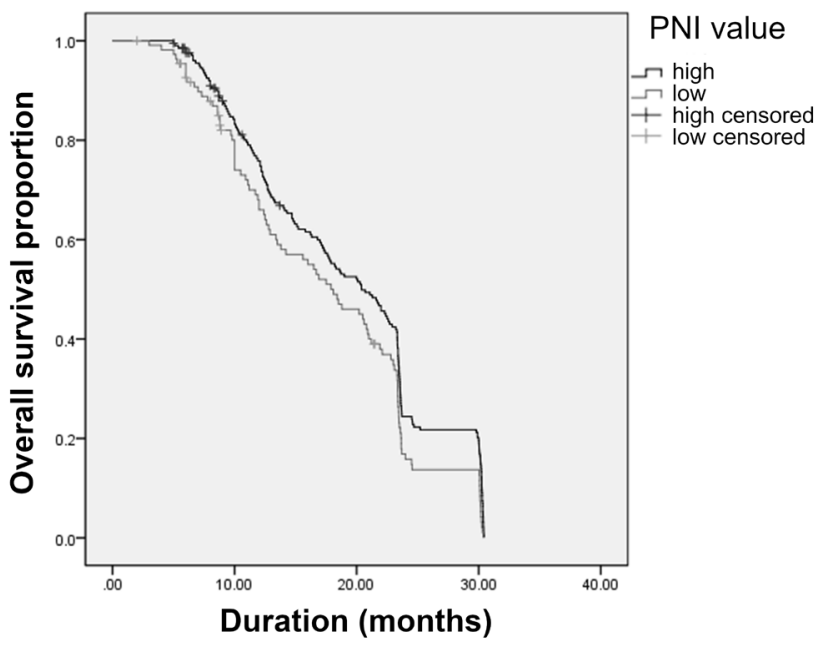

Figure 1. Kaplan-Meier survival curves according to the pretreatment PNI level.

were observed with respect to disease stage and treatment. Patients with a higher PNI $(\geq 50)$ tended to be the ones treated with chemotherapy $(\mathrm{p}=0.049)$ than those with lower PNI. Moreover, PNI was significantly higher in patients diagnosed with stage IIIB cancer compared with those with stage IV disease $(p<0.001)$. No significant correlation was observed between PNI and age, gender, smoking or pathology.

Prognostic value of PNI. The correlation between clinicopathological factors and OS is shown in Figure 1. The PNI values of all the patients ranged from 5.15 to 73.25 (mean, 48.1; median, 49.35). The cutoff value of the PNI for clinically significant malnutrition was set at below 50 in this study. Then, 315 patients were divided into low-PNI group $(n=179$; $56.8 \%)$ and high-PNI group $(n=136 ; 43.2 \%)$. The median OS of patients with low PNI (PNI $\leq 50)$ and high PNI (PNI $>50$ ) was 14.4 and 17.95 months, respectively, and low PNI was highly associated with a short survival time $(\mathrm{HR}=1.331$; 95\% CI: $1.05-1.688, \mathrm{p}=0.018)$. One-year OS rates of PNI $>50$ group were higher than those of PNI $\leq 50$ group $(74 \% ; 67 \%)$ (Figure 1).

PNI and other prognostic factors for OS. To further identify the risk factors linked to postoperative OS, PNI and other clinicopathologic factors were evaluated by univariate analysis and the Cox regression model. Univariate analysis (Table 3) showed that the significant prognostic factors for OS in advanced NSCLC patients were disease stage $(p=0.017)$, smoking $(\mathrm{p}=0.001)$, pathology $(\mathrm{p}<0.001)$ and PNI $(\mathrm{p}=0.018)$. All clinicopathological characteristics were further investigated in multivariate analysis. After multivariate analysis (Table 4$)$, we found that smoking $(\mathrm{p}<0.001)$, disease stage $(\mathrm{p}=0.005)$ and PNI $(\mathrm{p}=0.001)$ were significant independent predictors of OS. However, pathology $(p=0.423)$ had no influence on OS.
Table 3. Univariate analysis of clinicopathological parameters for the prediction of OS in patients with NSCLC.

\begin{tabular}{|c|c|c|c|}
\hline Parameters & $\begin{array}{c}\text { Univariate } \\
\text { HR }\end{array}$ & $\begin{array}{l}\text { analysis } \\
(95 \% \mathrm{CI})\end{array}$ & p-value \\
\hline Age (years) & & & 0.070 \\
\hline$<58$ & 1.00 & & \\
\hline$\geq 58$ & 1.244 & $0.982-1.576$ & \\
\hline Gender & & & 0.080 \\
\hline Female & 1.00 & & \\
\hline Male & 1.248 & $0.974-1.601$ & \\
\hline Smoking & & & 0.001 \\
\hline No smoking & 1.00 & & \\
\hline Smoking & 1.974 & $1.524-2.556$ & \\
\hline Disease stage & & & 0.017 \\
\hline IIIB & 1.00 & & \\
\hline IV & 0.749 & $0.592-0.949$ & \\
\hline Treatment & & & 0.113 \\
\hline Chemotherapy & 1.00 & & \\
\hline EGFR-TKIs & 0.801 & $0.609-1.054$ & \\
\hline PNI & & & 0.018 \\
\hline$\geq 50$ & 1.00 & & \\
\hline$<50$ & 1.331 & $1.05-1.688$ & \\
\hline Pathology & & & $<0.001$ \\
\hline $\mathrm{AD}$ & 1.00 & & \\
\hline SQ & 0.677 & $0.554-0.827$ & \\
\hline others & & & \\
\hline
\end{tabular}

$\mathrm{AD}$, adenocarcinoma; PNI, prognostic nutritional index; SQ, squamous cell carcinoma; EGFR-TKIs, epidermal growth factor receptor (EGFR)-tyrosine kinase inhibitors.

Table 4. Multivariate analysis of clinicopathological parameters for the prediction of OS in patients with NSCLC.

\begin{tabular}{lccc}
\hline Parameters & $\begin{array}{c}\text { Multivariate } \\
\text { HR }\end{array}$ & $\begin{array}{c}\text { analysis } \\
(\mathbf{9 5 \%} \mathbf{C I})\end{array}$ & p-value \\
\hline $\begin{array}{l}\text { Disease stage } \\
\text { IIIB }\end{array}$ & 1.00 & & 0.005 \\
IV & 0.703 & $0.550-0.897$ & \\
Smoking & & & $<0.001$ \\
$\quad$ No smoking & 1.00 & & \\
$\quad$ Smoking & 2.418 & $1.478-3.957$ & 0.001 \\
PNI & & & \\
$\geq 50$ & 1.00 & & 0.423 \\
$<50$ & 1.525 & $1.194-1.947$ & \\
Pathology & & & \\
AD & 1.00 & & \\
SQ & 1.151 & $0.816-1.626$ & \\
others & & & \\
\hline
\end{tabular}

AD, adenocarcinoma; PNI, prognostic nutritional index; SQ, squamous cell carcinoma; EGFR-TKIs, epidermal growth factor receptor (EGFR)-tyrosine kinase inhibitors. 


\section{Discussion}

PNI, determined by two factors, the serum albumin concentration and lymphocyte count in the peripheral blood, was used to assess the immunological and nutritional status of cancer patients after digestive surgery [9]. In 2011, Proctor et al. reported that Onodera's PNI could predict the outcome of cancer patients, regardless of the primary site of origin [8]. Yao et al. found that PNI was a useful indicator of prognosis in patients with malignant pleural mesothelioma [13]. Similar results can be seen in other cancers such as colorectal and hepatocellular carcinomas [11], and lung cancer is no exception.

Notably, many previous reports have shown that a lower PNI signifies a shorter OS in the in patients with completely resected NSCLC $[14,15]$. Studies about the prognostic value of the PNI in patients with advanced NSCLC are very few. In 2016, Sheng et al. studied 144 patients with advanced NSCLC following EGFR-TKIs and found that PNI was a significant prognostic factor [16]. In our study, we investigated PNI in 315 patients for advanced (IIIB/IV) NSCLC who received chemotherapy or EGFR-TKIs. After univariate and multivariate analysis, we found that PNI was independently associated with overall cancer-specific survival of patients $(p=0.001)$. Patients with a higher PNI had a better prognosis.

The mechanisms that regulate the association between PNI and the survival of patients with cancer are not yet completely elucidated. Several explanations have been proposed.

Firstly, malnutrition can be seen in various malignancies, especially in advanced cancers. Due to the characteristic of cancer rapid reproduction, large quantities of nutrients are consumed and deprived from the body, causing the impairment of normal metabolism. Besides, nutritional disorders have been reported to be associated with the severity of depression, anxiety and pain, which lead to poor outcomes in cancer patients [17]. Serum albumin, synthesized by hepatocytes, is commonly used to estimate the nutritional status [18]. Decreased albumin expression has been considered an indication of malnutrition and its drastic reduction often gives a hint of a contributor to cachexia, which is associated with reduced survival [19]. In addition, increasing evidence has emphasized the contributing role of the inflammatory response, which can exacerbate tumor-related malnutrition and the albumin reduction in many cancer patients.

Inflammatory mediators secreted by tumor, including tumor necrosis factor- $\alpha$ (TNF- $\alpha$ ) and interleukin-6 (IL-6) result in low appetite and thus affecting the nutritional intake. Some studies have suggested that hypoalbuminemia is caused by these cytokines, which all participate in downregulating the gene expression of albumin and decrease the synthesis of albumin [20]. Furthermore, inflammation can also promote and reflect tumor progression by affecting host immunity and the antitumor response. Therefore, nutrition plays a vital role in the process of the maintenance of immune function and malnutrition may have bad effects on the function of immune system.

The above-mentioned evidence suggests that hypoalbuminemia correlates with poor outcome in cancer patients. A study of 191 esophageal cancer patients after surgery demonstrated that an insufficient postoperative albumin recovery was a poor predictor of survival [21]. Another study conducted in 59 elderly patients with advanced NSCLC, who received chemotherapy or best supportive care, found that in elderly advanced NSCLC patients with poor performance status (PS), low serum albumin level was associated with poor prognosis in chemotherapy group [22]. A meta-analysis conducted to assess the prognostic significance of serum albumin in urothelial carcinoma found that reduced preoperative serum albumin level was an independent prognostic factor of urothelial carcinoma [23]. Besides, serum albumin level has been identified to have a prognostic impact on survival of patients with multiple cancer types [24-30].

On the other side, accumulating evidence support that the immunity is closely related to the occurrence and development of tumor [31]. Lymphocytes as important components of immune cells, have long been reported to inhibit the growth of cancer by T-cell-mediated immune response [32]. It is true that CD4+ T helper lymphocytes $(\mathrm{CD} 4+\mathrm{Th})$ and $\mathrm{CD} 8+\mathrm{T}$ lymphocytes work together to induce an immune response to tumor. When tumor antigens are presented to CD8+T lymphocytes, CD8+T lymphocytes are transferred into CD8+cytotoxic T lymphocyte (CTLs) to exhibit the activity against cancer. With direct roles of killing tumor cells, CD8+CTLs also increase tumor cell apoptosis by secreting cytokines such as interferon- $\gamma(\operatorname{IFN}-\gamma)[33,34]$, tumor necrosis factor (TNF). Additionally, substantial evidence shows that chronic inflammatory reactions contribute to promoting tumor growth and invasion. We found that CD4+Th became capable of enhancing the effect of CD8+CTLs and inducing antitumor inflammation response via generating and releasing interleukin-2. As discussed above, high concentrations of lymphocytes were shown to be strongly associated with antitumor activity and infection control.

Several reports support using the lymphocyte count as a prognostic factor. Mehrazin et al. observed that patients with lymphopenia risk had a worse prognosis in papillary renal cell carcinoma [35]. In 2005, Sato et al. reported that intraepithelial CD8+ tumor infiltrating lymphocytes were associated with a good prognosis in ovarian cancer [36]. Similarly, several studies suggested that there was a positive correlation between the infiltration of lymphocytes in tumor tissue and prognosis in breast, head and neck cancer patients [37-39].

In advanced patients with NSCLC, Lee and colleagues reported that the lymphocyte count was a significant prognostic factor [40], while Song et al. found that it was useful in patients with NSCLC treated with chemoradiotherapy [41]. 
Based on these reports, both the serum albumin and lymphocytes are obviously related to the prognosis of cancer patients, which may explain the association between low PNI and poor prognosis in cancer patients.

In our present study, we also found that the high PNI tend to be in patients of stage IIIB ( $\mathrm{p}<0.001)$ and treated with chemotherapy $(p=0.049)$. It is easy to understand that patients of stage IIIB have a better prognosis than that of stage IV. We know that stage IIIB has better nutritional and immune state than stage IV, which could explain why stage IIIB are more likely to have a higher PNI. As we know, chemotherapy leads to sickness and vomiting, then patients may lose appetite and have a rapid weight loss. Compared with chemotherapy, the side effects of EGFR-TKIs tend to be accepted [42]. However, in our present study, patients treated with EGFRTKIs have a lower PNI. Our explanation is that the number of enrolled patients was too small. If we have a large sample, maybe we can come to a completely different conclusion. Another reason is that some patients with EGFR-TKIs developed drug resistance early and refused further treatment.

In addition, we also explored other factors that may influence the OS of cancer patients, such as age, gender, smoking habits, pathology stage, historic types. As previous reports mentioned, age, male, smoking, patients with advanced stage were negativefactors that affect survival in lung cancer patients. However, significant differences were observed in patients with advanced clinical stage (IV) and those having smoking habits ( $\mathrm{p}$-value both $<0.05$ ). Age and gender were not correlated to survival of advanced NSCLC patients in our study.

This study has several limitations that should be considered when interpreting the results. Firstly, the number of patients is small, which may have potentially biased the results of our study. Secondly, the relapse free survival of patients was not statistically analyzed in the study, so the obtained results are correspondingly short of conviction.

In conclusion, we demonstrated that PNI was a favorable and promising marker to predict OS of patients with advanced (IIIB/IV) NSCLC. A low PNI is correlated with the poor prognosis of cancer patients. As to patients with decreased PNI, some alternative treatment methods can be provided, which may prolong their survival.

Acknowledgements: We thank Prof. Dianjie Lin of Provincial Hospital Affiliated to Shandong University for his encouragement and other staff at the Department of Respiratory Medicine of Shandong Provincial Hospital Affiliated to Shandong University for their assistance in collecting clinical data.

\section{References}

[1] BRAY F, FERLAY J, SOERJOMATARAM I, SIEGEL RL, TORRE LA etal. Global cancer statistics 2018: GLOBOCAN estimates of incidence and mortality worldwide for 36 cancers in 185 countries. CA Cancer J Clin 2018; 68: 394-424. https://doi.org/10.3322/caac.21492
[2] HAINSWORTH JD, CEBOTARU CL, KANAREV V, CIULEANU TE, DAMYANOV D et al. A phase II open-label, randomized study to assess the efficacy and safety of AZD6244 (ARRY-142886) versus pemetrexed in patients with non-small cell lung cancer who have failed one or two prior chemotherapeutic regimens. J Thorac Oncol 2010; 5: 1630-1636. https://doi.org/10.1097/JTO.0b013e3181e8b3a3

[3] YING HQ, DENG QW, HE BS, PAN YQ, WANG F et al. The prognostic value of preoperative NLR, d-NLR, PLR and LMR for predicting clinical outcome in surgical colorectal cancer patients. Med Oncol 2014; 31: 305. https://doi.org/10.1007/ s12032-014-0305-0

[4] AZAB BN, BHATT VR, VONFROLIO S, BACHIR R, RUBINSHTEYN $\mathrm{V}$ et al. Value of the pre-treatment albumin to globulin ratio in predicting long-term mortality in breast cancer patients. Am J Surg 2013; 206: 764-770. https://doi. org/10.1016/j.amjsurg.2013.03.007

[5] SMITH RA, BOSONNET L, RARATY M, SUTTON R, NOEPTOLEMOS JP et al. Preoperative platelet-lymphocyte ratio is an independent significant prognostic marker in resected pancreatic ductal adenocarcinoma. Am J Surg 2009; 197: 466-472. https://doi.org/10.1016/j.amjsurg.2007.12.057

[6] HE W, YIN C, GUO G, JIANG C, WANG F et al. Initial neutrophil lymphocyte ratio is superior to platelet lymphocyte ratio as an adverse prognostic and predictive factor in metastatic colorectal cancer. Med Oncol 2013; 30: 439. https://doi. org/10.1007/s12032-012-0439-x

[7] KASYMJANOVA G, MACDONALD N, AGULNIK JS, COHEN V, PEPE C et al. The predictive value of pre-treatment inflammatory markers in advanced non-small-cell lung cancer. Curr Oncol 2010; 17: 52-58. https://doi.org/10.3747/ co.v17i4.567

[8] PROCTOR MJ, MORRISON DS, TALWAR D, BALMER SM, FLETCHER CD et al. A Glasgow inflammation outcome study. Eur J Cancer 2011; 47: 2633-2641. https://doi. org/10.1016/j.ejca.2011.03.028

[9] NOZO E T, KIMURA Y, ISHIDA M, SAEKI H, KORENAGA $\mathrm{D}$ et al. Correlation of pre-operative nutritional condition with post-operative complications in surgical treatment for oesophageal carcinoma. Eur J Surg Oncol 2002; 28: 396-400. https://doi.org/10.1053/ejso.2002.1257

[10] MIGITA K, TAKAYAMA T, SAEKI K, MATSUMOTO S, WAKATSUKI $\mathrm{K}$ et al. The prognostic nutritional index predicts long-term outcomes of gastric cancer patients independent of tumor stage. Ann Surg Oncol 2013; 20: 2647-2654. https://doi.org/10.1245/s10434-013-2926-5

[11] NOZOE T, KOHNO M, IGUCHI T, MORI E, MAEDA T et al. The prognostic nutritional index can be a prognostic indicator in colorectal carcinoma. Surg Today 2012; 42: 532-535. https://doi.org/10.1007/s00595-011-0061-0

[12] KANDA M, FUJII T, KODERA Y, NAGAI S, TAKEDA S et al. Nutritional predictors of postoperative outcome in pancreatic cancer. Br J Surg 2011; 98: 268-274. https://doi. org/10.1002/bjs.7305

[13] YAO ZH, TIAN GY, WAN YY, KANG YM, GUO HS et al. Prognostic nutritional index predicts outcomes of malignant pleural mesothelioma. J Cancer Res Clin Oncol 2013; 139: 2117-2123. https://doi.org/10.1007/s00432-013-1523-0 
[14] QIU C, QU X, SHEN H, ZHENG C, ZHU L et al. Evaluation of prognostic nutritional index in patients undergoing radical surgery with nonsmall cell lung cancer. Nutr Cancer 2015; 67: 741-747. https://doi.org/10.1080/01635581.2015.1032430

[15] SHIMIZU K, OKITA R, SAISHO S, MAEDA A, NOJIMA $\mathrm{Y}$ et al. Preoperative neutrophil/lymphocyte ratio and prognostic nutritional index predict survival in patients with non-small cell lung cancer. World J Surg Oncol 2015; 13: 291. https://doi.org/10.1186/s12957-015-0710-7

[16] SHENG J, YANG YP, MA YX, QIN T, HU ZH et al. Low Prognostic Nutritional Index Correlates with Worse Survival in Patients with Advanced NSCLC following EGFR-TKIs. PLoS One 2016; 11: e0147226. https://doi.org/10.1371/journal.pone. 0147226

[17] CHABOWSKI M, POLANSKI J, JANKOWSKA-POLANSKA B, JANCZAK D, ROSINCZUK J. Is nutritional status associated with the level of anxiety,depression and pain in patients with lung cancer?. J Thorac Dis 2018; 10: 2303-2310. https://doi.org/10.21037/jtd.2018.03.108

[18] ARGILES JM, BUSQUETS S, STEMMLER B, LOPEZ-SORIANO FJ. Cancer cachexia: understanding the molecular basis. Nat Rev Cancer 2014; 14: 754-762. https://doi. org/10.1038/nrc3829

[19] FEARON K, STRASSER F, ANKER SD, BOSAEUS I, BRUERA E et al Definition and classification of cancer cachexia: an international consensus. Lancet Oncol 2011; 12: 489-495. https://doi.org/10.1016/S1470-2045(10)70218-7

[20] MCMILLAN DC, WATSON WS, O'GORMAN P, PRESTON T, SCOTT HR et al. Albumin concentrations are primarily determined by the body cell mass and the systemic inflammatory response in cancer patients with weight loss. Nutr Cancer 2001; 39: 210-213. https://doi.org/10.1207/ S15327914nc392_8

[21] MATSUDA S, NIIHARA M, TSUBOSA Y, SATO H, TAKEBAYASHI $\mathrm{K}$ et al. Clinical significance of postoperative recovery of serum albumin levels in patients with esophageal cancer whounderwent transthoracicesophagectomy. Surg Today 2016; 46: 1138-1145. https://doi.org/10.1007/s00595-015-1300-6

[22] IKEDA S, YOSHIOKA H, IKEO S, MORITA M, SONE N et al. Serum albumin level as a potential marker for deciding chemotherapy or best supportive care in elderly, advanced non-small cell lung cancer patients with poor performance status. BMC Cancer 2017; 17: 797. https://doi.org/10.1186/ s12885-017-3814-3

[23] LIU J, WANG F, LI S, HUANG W, JIA Y et al. The prognostic significance of preoperative serum albumin in urothelial carcinoma: a systematic review and meta-analysis. Biosci Rep 2018; 38: BSR20180214. https://doi.org/10.1042/ BSR20180214

[24] LONGO WE, VIRGO KS, JOHNSON FE, OPRIAN CA, VERNAVA AM et al. Risk factors for morbidity and mortality after colectomy for colon cancer. Dis Colon Rectum 2000; 43: 83-91. https://doi.org/10.1007/bf02237249

[25] ONATE-OCANA LF, AIELLO-CROCIFOGLIO V, GALLARDO-RINCON D, HERRERA-GOEPFERT R, BROMVALLADARES R et al. Serum albumin as a significant prognostic factor for patients with gastric carcinoma. Ann Surg Oncol 2007; 14: 381-389. https://doi.org/10.1245/s10434006-9093-x
[26] LIS CG, GRUTSCH JF, VASHI PG, LAMMERSFELD CA. Is serum albumin an independent predictor of survival in patients with breast cancer? JPEN J Parenter Enteral Nutr 2003; 27: 10-15. https://doi.org/10.1177/014860710302700110

[27] SEVE P, RAY-COQUARD I, TRILLET-LENOIR V, SAWYER $\mathrm{M}$, HANSON J et al. Low serum albumin levels and liver metastasis are powerful prognostic markers for survival in patients with carcinomas of unknown primary site. Cancer 2006; 107: 2698-2705. https://doi.org/10.1002/cncr.22300

[28] SHARMA R, HOOK J, KUMAR M, GABRA H. Evaluation of an inflammation-based prognostic score in patients with advanced ovarian cancer. Eur J Cancer 2008; 44: 251-256. https://doi.org/10.1016/j.ejca.2007.11.011

[29] WYID L, GUTTERIDGE E, PINDER SE, JAMES JJ, CHAN SY et al. Prognostic factors for patients with hepatic metastases from breast cancer. Br J Cancer 2003; 89: 284-290. https://doi.org/10.1038/sj.bjc.6601038

[30] BARRETO-ANDRADE JC, MEDINA-FRANCO H. Serum albumin is an independent prognostic factor for survival in soft tissue sarcomas. Rev Invest Clin 2009; 61: 198-204.

[31] HU S, ZHANG S, CAI T. [Immunochemotherapy for advanced non-small cell lung cancer: a meta-analysis]. Clinical Focus 2015; 30: 283-289.

[32] CHEN DS, MELLMAN I. Oncology meets immunology: the cancer-immunity cycle. Immunity 2013; 39: 1-10. https:// doi.org/10.1016/j.immuni.2013.07.012

[33] BEATTY G, PATERSON Y. IFN-gamma-dependent inhibition of tumor angiogenesis by tumor-infiltrating CD4+ T cells requires tumor responsiveness to IFN-gamma. J Immunol 2001; 166: 2276-2282. https://doi.org/10.4049/jimmunol.166.4.2276

[34] MOJIC M, TAKEDA K, HAYAKAMA Y. The dark side of IFN-gamma: its role in promoting cancer immunoevasion. Int J Mol Sci 2017; 19: E89. https://doi.org/10.3390/ ijms 19010089

[35] MEHRAZIN R, UZZO RG, KUTIKOV A, RUTH K, TOMASZEWSKI JJ et al. Lymphopenia is an independent predictor of inferior outcome in papillary renal cell carcinoma. Urol Oncol 2015; 33: 388. e19-25. https://doi.org/10.1016/j. urolonc.2014.06.004

[36] SATO E, OLSON SH, AHN J, BUNDY B, NISHIKAWA H et al. Intraepithelial CD8+ tumor-infiltrating lymphocytes and a high $\mathrm{CD} 8+$ /regulatory $\mathrm{T}$ cell ratio are associated with favorable prognosis in ovarian cancer. Proc Natl Acad Sci U S A 2005; 102: 18538-18543. https://doi.org/10.1073/ pnas.0509182102

[37] LOI S, SIRTAINE N, PIETTE F, SALGADO R, VIALE G et al. Prognostic and predictive value of tumor-infiltrating lymphocytes in a phase III randomized adjuvant breast cancer trial in node-positive breast cancer comparing the addition of docetaxel to doxorubicin with doxorubicin-based chemotherapy: BIG 02-98. J Clin Oncol 2013; 31: 860-867. https:// doi.org/10.1200/JCO.2011.41.0902

[38] BALERMPAS P, RODEL F, WEISS C, RODEL C, FOKAS E. Tumor-infiltrating lymphocytes favor the response to chemoradiotherapy of head and neck cancer. Oncoimmunology 2014; 3: e27403. https://doi.org/10.4161/onci.27403 
[39] MAHMOUD SM, PAISH EC, POWE DG, MACMILLAN RD, GRAINGE MJ et al. Tumor-infiltrating CD8+ lymphocytes predict clinical outcome in breast cancer. J Clin Oncol 2011; 29: 1949-1955. https://doi.org/10.1200/ JCO.2010.30.5037

[40] LEE S, EO W, JEON H, PARK S, CHAE J. Prognostic Significance of Host-related Biomarkers for Survival in Patients with Advanced Non-Small Cell Lung Cancer. J Cancer 2017; 8: 2974-2983. https://doi.org/10.7150/jca.20866
[41] SONG X, CHEN D, YUAN M, WANG H, WANG Z. Total lymphocyte count, neutrophil-lymphocyte ratio, and platelet-lymphocyte ratio as prognostic factors in advanced non-small cell lung cancer with chemoradiotherapy. Cancer Manag Res 2018; 10: 6677-6683. https://doi.org/10.2147/ CMAR.S188578

[42] ZHOU C, WU YL, CHEN G, FENG J, LIU XQ et al. Erlotinib versus chemotherapy as first-line treatment for patients with advanced EGFR mutation-positive non-small-cell lung cancer (OPTIMAL, CTONG-0802): a multicentre, open-label, randomised, phase 3 study. Lancet Oncol 2011; 12: 735-742. https://doi.org/10.1016/S1470-2045(11)70184-X 